\title{
THE RELATIONSHIP BETWEEN PRE-HOSPITAL FACTORS AND GLASGOW OUTCOME SCALE IN HEAD INJURED PATIENTS WITH GLASGOW COMA SCALE 9-13 IN PUBLIC HOSPITAL DR. SAIFUL ANWAR, MALANG
}

\author{
Yowargana Faye ${ }^{1 *}$, Siswanto $^{2}$, Prasetyadjati Ari ${ }^{3}$, Santoso Moch. Istiadjid Eddy ${ }^{4}$ \\ ${ }^{1}$ Resident of the Medical Education Program for Emergency Medicine Specialist, \\ Faculty of Medicine, University of Brawijaya, Indonesia \\ ${ }^{2}$ Staff of Department of Public Health, University of Brawijaya, Indonesia \\ ${ }^{3}$ Staff of Department of Emergency Medicine, Faculty of Medicine, University of Brawijaya, \\ Indonesia \\ ${ }^{4}$ Professor of Neurosurgery, Faculty of Medicine, University of Brawijaya, Indonesia \\ *E-mail: fayebright@gmail.com
}

\begin{abstract}
Traumatic head injury is one of the main health problems and socio-economic problems causing death and disability in adults and children in the world. The incidence of head injuries worldwide is increasing, mainly due to increased use of motorized vehicles, especially in middle- and low-income countries. The better head injury outcome is achieved when worsening secondary factors which result in a reduction in cerebral perfusion to the injured brain can be prevented or respond to therapy. To analyze the relationship between the independent variables of pre-hospital factors, i.e. age, initial GCS upon arrival at the ER, hypoxia, and systolic blood pressure, and the dependent variable of trauma outcome 3 months after the event assessed by the Glasgow Outcome Scale (GOS). An analytical observational study with a cohort study approach is employed to analyze the relationship between pre-hospital risk factors, i.e. age, initial GCS upon arrival at ER, hypoxia, and systolic blood pressure and the Glasgow Outcome Scale (GOS) 3 months after the event. Of the 36 patients, the relationships between the age variable and the GOS and between the blood pressure variable and the GOS showed p-values of 0.253 and 0.131 greater than $\alpha$ $5 \%$. Thus, it can be concluded that the aforementioned two relationships were not significant. Difference test on the group with satisfactory GOS outcome and the group with unsatisfactory GOS outcome was conducted to examine the relationship between the oxygen saturation variable and the GCS. Significance values of 0.374 and 0.093 were greater than $\alpha>0.050$. Thus, it can be concluded that the differences were not significant. There was no significant relationship between patients' age, blood pressure, oxygen saturation, and the initial GCS and the outcome of head injured patients with GCS 9-13.
\end{abstract}

\section{KEY WORDS}

Head injury, pre-hospital factors, Glasgow Outcome Scale (GOS).

The traumatic head injury is one of the main health problems and socio-economic problems causing death and disability in adults and children in the world. The incidence of head injuries worldwide is increasing, mainly due to increased use of motorized vehicles, especially in middle- and low-income countries (Roozeenbek et al., 2013). About 10 percent of head injured patients experience moderate head injury, i.e. head injury with GCS 9-13 after resuscitation. Most patients with moderate head injury are still alive at the scene and taken to the emergency room for stabilization and evaluation.

The management of patients with head injury in the pre-hospital and intensive care phase has improved and based on existing researches and research evidence. The Brain Trauma Foundation (BTF) develops the management guidelines published in 2007. One of the main concepts is not all nerve damage in traumatic head injury occur at the time of the event but evolved in the next hours or days. Therefore, the better head injury outcome is achieved when worsening secondary factors which result in a reduction in cerebral perfusion to the injured brain can be prevented or respond to therapy. 
The high incidence of patients with head injury and the high mortality and disability in patients with moderate head injury are the backgrounds of this research. The absence of previous studies on pre-hospital factors such as age, GCS, hypoxia, and systolic blood pressure are problems examined by the researchers as some factors affecting the outcome of patients with moderate head injury in RSSA (Public Hospital Saiful Anwar, Rumah Sakit Saiful Anwar), Malang in a comprehensive trauma handling series according to the concept of immediate assessment, triage, resuscitation, diagnosis, and therapeutic intervention from the scene to the rehabilitation.

The researchers aim to analyze the relationship between the independent variables of pre-hospital factors, i.e. age, initial GCS upon arrival at ED, hypoxia, and systolic blood pressure and the dependent variable of trauma outcome 3 months after the event assessed by the Glasgow Outcome Scale (GOS) in RSSA, Malang.

\section{METHODS OF RESEARCH}

This research employs an analytic observational study with a cohort study approach to examine the relationship between pre-hospital risk factors and the Glasgow Outcome Scale (GOS) 3 months after the event. The research samples were all head injured patients with the GCS 9-13 in the RSSA's ER compliant with the inclusion criteria during the research period. With consecutive sampling technique, 36 patients were taken.

Inclusion criteria:

- Patients with a head injury caused by blunt trauma with the initial GCS 9-13 upon arrival at RSSA triage;

- Age $>18$ years old.

Exclusion Criteria

- Patients with an unclear history of trauma;

- Patients with a head injury as well as injuries in other organs;

- Patients underwent head surgery regarding the suffered head injury.

Data on age, GCS, oxygen saturation, systolic blood pressure, and the GOS 3 months after the event were analyzed using descriptive statistics and presented in the form of distribution frequency table. Data on age and the GOS 3 months after the event as well as systolic blood pressure and the GOS 3 months after the event were analyzed using chisquare test if data met the requirements or Fisher's test if data did not meet the requirements. Data on GCS and the GOS 3 months after the event as well as oxygen saturation and the GOS 3 months after the event were analyzed using Independence T-Test if data were normally distributed and Mann Whitney U-test if data were not normally distributed. All variables were analyzed using a 95\% confidence level, $\alpha=0.05$ was significant if $p$-value $<0.05$. Multivariate analysis was performed with multiple logistic regression method to determine the most influencing factors of GOS 3 months after the event where $p$-value $>0.25$ was not included.

\section{RESULTS OF STUDY}

Of the 36 patients, 6 (16.67\%) patients had unsatisfactory GOS outcome (GOS 1-3) and $30(83.33 \%)$ patients had satisfactory GOS outcome (GOS 4-5).

The relationships between the age variable and the GOS as well as between the blood pressure variable and the GOS were analyzed using chi-square analysis. The results showed p-values of 0.253 and 0.131 greater than $\alpha 5 \%$. Thus, it can be concluded that the aforementioned two relationships were not significant (an insignificant relationship). The correlation coefficients obtained were 0.266 and 0.244 , which meant the relationship between the blood pressure variable and the GOS was in the range of $0.20-0.40$ or in the low correlation category.

Regarding the oxygen saturation variable and the GCS, Mann Whitney difference test was conducted on the group with satisfactory GOS outcome and the group with unsatisfactory GOS outcome. The results showed significance values of 0.374 and 0.093 
greater than $\alpha>0.050$. Thus, it can be concluded that there were no significant differences (insignificant differences) between oxygen saturation values and the GCS in the groups with satisfactory and unsatisfactory GOS outcome.

Table 1 - The Summary of Pre-Hospital Factors Affecting GOS

\begin{tabular}{|c|c|c|c|}
\hline \multirow{2}{*}{ Variable } & \multicolumn{2}{|c|}{ GOS Outcome } & \multirow{2}{*}{$p$-value } \\
\cline { 2 - 3 } & Unsatisfactory (GOS 1, 2, and 3) & Satisfactory (GOS 4\&5) & \\
\hline \multicolumn{2}{|c|}{ Age } & \multirow{2}{*}{0.253} \\
\hline Young Adults & $2(9.1 \%)$ & $4(90.9 \%)$ & \multirow{2}{*}{0.131} \\
\hline Middle age & $1(20.0 \%)$ & $6(66.0 \%)$ & \\
\hline Old Age & $3(33.3 \%)$ & $0(0.0 \%)$ & \\
\hline \multicolumn{2}{r|}{ Blood pressure } & $27(87.1 \%)$ \\
\hline Hypotension & $0(0.0 \%)$ & $3(60.0 \%)$ & 0.094 \\
\hline Normotension & $4(12.9 \%)$ & $10.40 \pm 1.354$ & 0.374 \\
\hline Hypertension & $2(40.0 \%)$ & $97.93 \pm 2.363$ & \\
\hline GCS & $9.50 \pm 1.225$ & 30 & \\
\hline SaO2 & $95.83 \pm 4.356$ & 6 & \\
\hline Total $(n)$ & 6 & &
\end{tabular}

The multivariate analysis was performed with multiple logistic regression method to determine the most influencing factors of GOS 3 months after the event where p-value $>0.25$ was not included. The analysis results and discussion for the logistic regression test with variable $\mathrm{Y}$ (the GOS) are as follows:

Table 2 - Odds Ratio

\begin{tabular}{|c|c|c|c|c|c|}
\hline Variable & B & Wald & Sig. & Exp(B) & Note \\
\hline TD_sist (1) & 1.587 & 1.917 & 0.166 & 4.887 & Not significant \\
\hline GCS & 0.656 & 1.994 & 0.158 & 1.927 & Not significant \\
\hline
\end{tabular}

The analysis results of the systolic blood pressure and the GCS variables showed the Wald values of 1.917 and 1.994 with p-values (Sig.) of 0.166 and 0.158 . A smaller Wald value than the chi-square value or a greater $p$-value than $\alpha(0.05)$ indicated that there was no significant influence between systolic blood pressure and GCS variables and GOS variable.

\section{DISCUSSION OF RESULTS}

The head injured patients with GCS 9-13 at the emergency department were mostly male than female patients $(77.78 \%: 22.23 \%=3.5: 1)$. In the age groups, there were $61.1 \%$ of young adults (18-39 years), $13.8 \%$ of middle age (40-59 years) and $25 \%$ of old age (>60 years). These data are consistent with epidemiological data on head injury in which the risk factors for head injury are more men than women, increasing age, and alcohol intoxication. There are 3 distributions in morbidity according to age, i.e. children under 4 years, young adults (15-25 years), and old age over 75 years (Rosado et al., 2011).

Assessment of the head trauma healing outcome was determined 3 months after the event by examining the GOS based on the interviews results with patients or families. Of the 36 patients as the research sample, 6 people $(16.67 \%)$ experienced unsatisfactory trauma outcome (GOS 1-3) and 30 people experienced satisfactory trauma outcome (GOS 4-5). It was not much different from the moderate head injury mortality rate of around $20 \%$ (Heeggard \& Biros, 2014).

In the blood pressure variable, there were no patients with systolic blood pressure in the hypotensive category $(<90 \mathrm{mmHg})$. It was due to the selection bias in which patients with thoracic, abdominal, and limb injuries were excluded. Isolated head injury rarely causes hypotension, except at the pre-terminal stage (Wring \& Merk 2016).

In the oxygen saturation (SaO2) variable, there were no patients with oxygen saturation in hypoxia condition $(<90 \%)$. It was due to selection bias in which patients with facial trauma potentially experience airway obstruction and patients with chest and lung wall injuries 
potentially experience respiratory and oxygenation mechanisms were excluded. Consequently, there was no sample of patients in hypoxia.

In the GCS variable, the average GCS score in the group with unsatisfactory GOS outcome was lower of $9.50 \pm 1.225$, while the average GCS score in the group with satisfactory GOS outcome was $10.40 \pm 1.354$.

In this research, the relationship between the age variable and the GOS was not significant (insignificant relationship). In some previous writings and research, age was associated with worse outcome. However, some research results also showed that there was no relationship between age and head trauma outcome (Kulesza et al., 2015). However, a distinctive study with a sample of 12,675 patients with moderate head injury from 1999 to 2005 showed that age was not related to unsatisfactory outcome 6 months after the event (Fabbri et al., 2008). In general, age is a prognostic factor affecting the outcomes in patients with head injury. Nevertheless, age has no effect on patients with moderate head injury. These research results were similar to the previous research results that age was not a prognostic factor resulting from head injury in patients with moderate head injury or head injured patients with GCS 9-13.

In this research, the relationship between the systolic blood pressure variable and the GOS was not significant (insignificant relationship). Similar to the previous research, systolic blood pressure had no significant relationship with head trauma outcome in moderate head injury. It was due to selection bias in which there was no patient in the hypotensive condition and too few patients with hypertension, making the results were not statistically significant. However, the principle of moderate head trauma management is that all systemic conditions causing neurological deterioration in patients with head injury should be avoided including hypotension and hypoxia because one episode of hypotension is associated with a doubled mortality. Hypovolemic shock condition can be seen in multiple traumas, large blood loss from lacerations in the scalp, or subgaleal hematoma in children. Vasopressors can be used if fluid and blood resuscitation is not effective (Wring \& Merk 2016).

The results of previous studies showed that hypoxia, i.e. oxygen saturation of less than $90 \%$, was associated with worse outcome (Kulesza et al., 2015). Therefore, in this research, the oxygen saturation variable was divided into hypoxia category (Sao2 <90\%) and nonhypoxia category (Sao2 $\geq 90$ ). None of the 36 patients had oxygen saturation in the hypoxia category. There was no significant difference (insignificant difference) of the $\mathrm{SaO} 2$ value in the satisfactory and unsatisfactory groups of the GOS variable. Thus, it can be concluded that oxygen saturation in blood did not influence the head trauma outcome. Previous research by Fabbri et al. in 2008 stated that 6 variables were associated with unsatisfactory moderate head injury outcome, i.e. cranial base fracture, subarachnoid hemorrhage, coagulopathy, subdural hemorrhage, modified Marshal category, and GCS. From the above explanation, it can be concluded that hypoxia is not a prognostic factor for patients with moderate head injury because generally isolated head injured patients with GCS 9-13 taken to hospital are not in hypoxia. It may be due to the patient's reflex to keep the airway from being obstructed and the health workers who already recognize the risk of airway obstruction by blood or vomit do good management to maintain airway patency.

In this research, the initial GCS of head injured patients with the satisfactory outcome and the initial GCS of head injured patients with the unsatisfactory outcome had no significant difference (insignificant difference). The previous research by Kulesza et al. in 2015 provided strong evidence of the GCS prognosis value on the arrival and GCS motor score. Furthermore, Balestreri et al.'s research in 2004 with a sample of 384 people collected from 1992 to 2001 showed that the initial GCS on the arrival in the ER in patients from 1997 onwards could not predict the head injury outcome. Hence, the predictive value of GCS needed to be considered. These research results were in line with previous studies that initial GCS was not related to the head injury outcome. It might due to the dynamic nature of GCS and the initial GCS might get worse. In addition, it was influenced by other conditions outside the intracranial, so ideally GCS assessment was conducted when the condition was stable in the ER and fluid resuscitation had been performed. 


\section{CONCLUSION}

From the data analysis and discussion of the relationship between the variables in this research, there are some conclusions which complement new knowledge in the service process and relief efforts for head injury in the ER, i.e.:

- Patient age was not associated with outcome of head injured patients with GCS 9-13.

- Blood pressure in normotension and hypertension was not associated with outcome of head injured patients with GCS 9-13.

- Oxygen saturation in non-hypoxia condition was not associated with outcome of head injured patients with GCS 9-13.

- Initial GCS was not associated with outcome of head injured patients with GCS 9-13.

In patients with moderate head injury, hypotension and hypoxia are pre-hospital factors associated with a poor prognosis. Thus, by excluding hypotension and hypoxia, the factors of age, blood pressure, oxygen saturation, and GCS were not associated with moderate head injured patient outcome. The following are the suggestions or recommendations:

- Patient age was not a factor influencing isolated head injury outcome with initial GCS 9-13. Hence, extra cranial disease may be found in patients over the age of 60 years or differences in clinical management may be related to the patient's degenerative state. A good outcome can be achieved with standard management for patients with moderate head injury.

- Patients with moderate head injury must be prevented from the hypotensive and hypoxic episodes because these episodes are associated with a worse head injury outcome. As indicated by this research results, in a condition without hypotension and hypoxia, the vital signs of systolic blood pressure and oxygen saturation were not associated with head injury outcome.

- Initial GCS was not associated with head injury outcome 3 months after the event. It is necessary to conduct research to examine the prognostic factors associated with head injury outcome, whether in independent, assimilative or integrative manner.

- The prognosis calculator for head injury on the internet can be used wisely.

- Further research needs to be conducted to find better prognostic factors.

The research limitation is it was only conducted in 1 hospital, so patients with head injury as the research subject were limited to hospitalized patients in RSSA only. Another limitation is no data center for patients with head injury, making patients fulfilling inclusion criteria are not included as the sample or cannot be contacted to assess the outcome 3 months after the event. The last limitation is the research results is the associations, so it does not show a causal relationship.

\section{REFERENCES}

1. Andriessen, T. M. J. C., Jacobs, B., \& Vos, P. E. (2010). Clinical characteristics and pathophysiological mechanisms of focal and diffuse traumatic brain injury. J. Cell. Mol. Med, 14(10), 2381-2392

2. Alson, R. L. (2012). Head Trauma' in Campbell: International trauma life support for emergency care provider. New Jersey: Pearson Education.

3. Badjatia, N., et al. (2007). Guidelines for prehospital management of traumatic brain injury. Brain Trauma Foundation.

4. Balestreri, M., Czosnyka, M., Chatfield, D. A., Steiner, L., Schmidt, E. A., Smielewski, P., Matta, B. J., Pickard, J. D. (2004). Predictive value of Glasgow coma scale after brain trauma: change in trend over the past ten years. J Neurol Neurosurg Psychiatry, 75(1): 161-2

5. Basmatika, I. (2013). Cedera otak sekunder, (Unpublished paper). Medical Faculty of Udayana University, Bali

6. Basuki, W. S., Suryono, B., \& Saleh, S. C. (2015). Penatalaksanaan perioperatif cedera kepala traumatik berat dengan tanda cushing. Jurnal Neuroanestesi Indonesia, 4(1), 3442 . 
7. Berry, C., Ley, E. J., Bukur, M., Malinoski, D., Margulies, D. R., Mirocha, J., \& Salim, A. (2012). Redefining hypotension in traumatic brain injury. Injury, Int. J.Care Injured, 43(2012), 1833-1837.

8. Boyle, M., Wallis, J., Suryanto. (2016). Time to improve pre-hospital care in developing countries. Australasian Journal of Paramedicine, 13(3), retrieved from https://ajp.paramedics.org/index.php/ajp/article/view/538

9. Brenner, M., Stein, D., Hu, P., Kofera, J., Wooford, M., \& Scalea, T. (2012). Association between early hyperoxia and worse outcomes after traumatic brain injury. Arch surg, 147(11):1042-6

10. Carson, S., et al. (2007). Guideline for the management of severe traumatic injury. Jounal of neurotrauma, 24(1), 7-14

11. Dinsmore, J. (2013). Traumatic Brain Injury: an Evidence-based Review of Management. Retrieved from http://ceaccp.oxfordjournals.org.

12. Dinh, M. M., Bein, K., Roncal, S., Byrne, C. M., Petchell, J., Brennan, J., (2013). Redefining the golden hour for severe head injury in an urban setting: The effect of prehospital arrival times on patient outcomes. Injury, Int. J. Care Injured , 44(2013), 606610

13. Departemen Kesehatan. (2013). Laporan Riset Kesehatan Dasar (Riskesdas) Badan Litbangkes Depkes RI.

14. Fabbri, A., Servadei, F., Marchesini, G., Steing, S. C., \& Vandell, A. (2007). Early predictors of unfavourable outcome in subjects with moderate head injury in the emergency department. J Neurol Neurosurg Psychiatry 79(5):567-73

15. Fildes, J., \& Meredith, J. W. (2018). Advance Trauma Life Support for Doctors Student Course Manual. Chicago USA: American College of Surgeons Committee on Trauma.

16. Fuller, G., Hasler, R. M., Mealing, N., Lawrence, T., Woodford, J. P., \& Lecky, F. (2014). The association between admission systolic blood pressure and mortality in significant traumatic brain injury : A multi center cohort study. Injury. Int. J. Care Injured, 45(2014), 612-617.

17. Gunderson, M. (2015). Principle of EMS design' in Cone, D C: Emergency Medical Services Clinical Practice and Systems Oversight. United Kingdom: NAEMSP.

18. Haddad, H. S., \& Arabiz. Y.M. (2012). Critical care management of severe traumatic brain injury in adult. Scandinavian Journal of Trauma, Resuscitation and Emergency Medicine, 20(12), Retrieved from https://doi.org/10.1186/1757-7241-20-12

19. Harmsen, A. M. K., Giannakopoulos, G. F., Moerbeeka, P. R., Jansma, E. P., Bonjer, H. J., Bloemers, F. W. (2015). The Influence of Prehospital Time on Trauma Patients Outcome: A systematic review. Injury, Int. J. Care Injured, 46(2015), 602-610

20. Härtl, R., Gerber, L. M., Lacono, L., Ni, Q., Lyons, K., \& Ghajar, J. (2006). Direct

21. Transport Within An Organized State Trauma System Reduce Mortality in

22. Patient With Severe Traumatic Brain Injury. J Trauma, 2006(60), 1250-1256.

23. Hartoyo, M., Raharjo, S. S., \& Budiyati. (2012). Predictor's Factors of Mortality of Patients Suffering from Severe Head Injury in Emergency Department at General Hospital Tugurejo Semarang. Jurnal Riset Kesehatan 1 (3), 175-182.

24. Heeggard, W. G., \& Biros, M. H. (2014). Head Trauma: Rosen Emergency Medicine Concept and Clinical Practice. Elservier: Philadelphia

25. Kaye, H. (2005). Essential Neurosurgery Traumatic brain injury: Changing concepts and approaches. Chinese Journal of Traumatology, 19(2016), 3-6.

26. Kulesza, B., Nogalski, A., Kulesza, T., \& Prystupa, A. (2015). Prognostic Factors in Traumatic Brain Injury and Their Association with Outcome. Journal of Pre-Clinical and Clinical Research, 9(2), 163-166.

27. Manley, G., Knudson, M., Morabito, D., Damron, S., Erikson, V., \& Pitts, L. (2001). Hypotension, Hypoxia and Head injury frequency, duration and consequences. Arch Surg, 1(36), $1118-1123$.

28. Mayumi, P., Greco, T., Alexander, D., \& Giza, M., (2013). The pathophysiology of traumatic brain injury at a glance. Dis Model Mech, 6(6), 1307-1315. 
29. McLean, B., Zimmerman, J. L., \& Baldisseri, M. (2007). Fundamental Critical Care Support Society of Critical Care Medicine. Illinois: Mount Prospect.

30. Pitt, E., \& Pusponegoro, A. (2005). Prehospital Care in Indonesia. Emerg Med J, 22(2), 144-147.

31. Keputusan Menteri Kesehatan Republik Indonesia nomor 856/Menkes/SK/IX/2009

32. Prins, M., Greco, T., Alexander, D., \& Giza, C. C. (2013). The pathophysiology of traumatic brain injury at a glance. Disease Models \& Mechanisms, 6(6), 1307-1315.

33. Reed, A. R., \& Welsh, D. G. (2002). Secondary injury in traumatic brain injury patients-a prospective study. South African Medical Journal, 2002(92), 221-224.

34. Rosado, L. S., Simons, M., \& Jagoda, A. (2011). Trauma: A Comprehensive Emergency Medicine Approach. New York: Cambridge University Press.

35. Roozenbeek, B., Maas, A. I. R., \& Menon, D. K. (2013). Changing patterns in the epidemiology of traumatic brain injury. Nature Review Neurology, 9(4), 231-236.

36. Sasongko, J., Niryana, W., \& Golden, N. (2012). Risk Factors for Neuroworsening of Moderate Hea Injury Cases in Emergency Department Sanglah General Hospital BaliIndonesia. Bali Medical Journal (BMJ), 1(1), 29-31.

37. Shukla, D., Devi, I. B., \& Agrawal, A. (2011). Outcome Measures for Traumatic Brain Injury. Clinical Neurology and Neurosurgery, 113(2011), 435-441.

38. Spaite, D. W., et al. (2017). The Effect of Prehospital Hypoxia and Hypotension on Outcome in Major Traumatic Brain Injury: A Deadly Combination, Annals of emergency medicine Med, 69(1), 62-72

39. Sobrino, J., \& Shafi S. (2013). Timing and causes of death after injuries. Proc (Bayl Univ Med Cent), 26(2), 120-123

40. Susilawati, D. (2010). Hubungan Waktu Prehospital Dan Nilai Tekanan Darah Dengan Survival Dalam 6 Jam Pertama Pada Pasien Cedera Kepala Berat Di IGD RSUP Dr. M. Djamil-Padang Tahun 2010 (Unpublished Thesis). Nursery Faculty, Andalas University, Indonesia.

Tohme, S., Delhumeau, C., Zuercher, M., Haller, G., \& Walde, B. (2014). Prehospital risk factors of mortality and impaired consciousness after severe traumatic brain njury: an epidemiological study. Scandinavian Journal of Trauma Resuscitation and Emergency Medicine,22 (1), retrieved from https://doi.org/10.1186/1757-7241-22-1

41. Werner, C., \& Engelhard, K. (2007). Pathophysiology of traumatic brain injury. British Journal of Anaesthesia, 99(1), 4-9.

42. Wring, D.W., \& Merk L. H. (2016). Tintinalli's Emergency Medicine a Comprehensive Study Guide. New York: Mc Graw-Hill Education.

43. Yan, E. B., Hellewell, S. C., Bellander, B. M., Agyapomaa, D. A., \& Kossmann, M. C. M. (2011). Post-Traumatic Hypoxia Exacerbates Neurological Deficit, Neuroinflammation and Cerebral Metabolism in Rats with Diffuse Traumatic Brain Injury. Journal of Neuroinflammation, 8 (147) 1-16.

44. Zainayah, M. (2007). Pengaruh Kualitas Manajemen Prahospital dan Durasi Hospital terhadap RTS Pasien Cedera Kepala (Unpublished Thesis). Medical Faculty, Brawijaya University, Indonesia. 